\title{
KAJIAN ERGONOMI SARANA PENDUKUNG PROSES BELAJAR TERHADAP KELUHAN GOTRAK MAHASISWA INSTITUSI PENDIDIKAN X
}

\author{
Valyaty Frisa Aryadi ${ }^{1}$, Indri Hapsari Susilowati ${ }^{2}$ \\ Magister Keselamatan dan Kesehatan Kerja ${ }^{1}$, Departemen Keselamatan dan Kesehatan Kerja ${ }^{2}$ \\ Fakultas Kesehatan Masyarakat, Universitas Indonesia \\ vty353@gmail.com¹, indri@ui.ac.id²
}

\begin{abstract}
The quality of good learning is influenced by the characteristics of classroom facilities, where in a classroom must have the means to support the learning process at least chairs, desks, blackboards, and LCD projectors. The design of facilities that support the learning process that does not conform to the principles of ergonomics can lead to the risk of muscle and skeletal disorders. This study aims to examine and provide an overview of the ergonomics of learning process support facilities available in the classroom of Educational Institution X. The research was conducted in January - July 2021. Based on the results, it is known that the design of learning process support facilities skeletal muscle in students. Complaints of skeletal muscle disorders were felt by $97.61 \%$ of students on their body parts and related significantly to awkward posture when they studied in the classroom required remedial measures by redesigning existing learning support facilities and or urging students to choose a place Sit comfortably so as not to complain of skeletal muscle disorders.
\end{abstract}

Keyword : Ergonomic, Study Posture, MSDs

\begin{abstract}
ABSTRAK
Kualitas pembelajaran yang baik dipengaruhi oleh karakteristik fasilitas kelas belajar, dimana dalam sebuah ruang kelas harus memiliki sarana pendukung proses belajar minimal kursi, meja, papan tulis, dan LCD proyektor. Perancangan desain sarana pendukung proses belajar yang tidak sesuai prinsip ergonomi dapat menyebabkan risiko gangguan otot dan tulang rangka. Penelitian ini bertujuan untuk mengkaji dan memberi gambaran terkait ergonomi sarana pendukung proses belajar yang terdapat pada ruang kelas Institusi Pendidikan X. penelitian dilakuan pada Januari - Juli 2021. Berdasarkan hasil penelitian diketahui bahwa desain sarana pendukung proses belajar tidak sesuai dengan prinsip ergonomi dan menyebabkan keluhan gangguan otot rangka pada mahasiswa. Keluhan gangguan otot rangka dirasakan oleh $97,61 \%$ mahasiswa pada bagian-bagian tubuhnya dan berhubungan bermakna dengan postur janggal pada saat mereka belajar di ruang kelas diperlukan adanya langkah perbaikan dengan mendesain ulang sarana pendukung proses belajar yang ada dan atau menyerukan kepada mahasiswa agar memilih tempat duduk yang nyaman agar tidak mengeluhkan gangguan otot rangka.
\end{abstract}

Kata Kunci : Ergonomi, Gotrak, Postur Belajar,

\section{PENDAHULUAN}

Perkembangan ilmu pengetahuan dan teknologi (IPTEK) yang semakin pesat memacu terciptanya berbagai jenis peralatan kerja yang canggih di berbagai sektor. Hal tersebut juga berdampak pada dunia pendidikan khususnya pada metode belajar-mengajar yang semakin modern. Kualitas pembelajaran yang baik dipengaruhi oleh karakteristik ruang kelas (Ali Rohmad, dalam Rifqi Alim 2012).

Ruang kelas merupakan salah satu ruangan yang penting yang harus ada di suatu instansi pendidikan, karena ruang kuliah berguna sebagai sarana belajarmengajar. Sarana pendukung proses belajar yang diperlukan dalam ruang kuliah antara lain kursi, meja, papan tulis, dan LCD pyoyektor (Ristekdikti, 2019). Ruang kuliah yang ergonomis tentunya akan 
membuat seseorang merasa nyaman di dalam melakukan aktivitasnya di ruang tersebut.

Akan tetapi, kaidah ergonomi sampai saat ini belum banyak diterapkan dalam mendesain ruang kuliah dengan perangkat pendukungnya. Ruang kuliah yang semula hanya dilengkapi papan tulis dan kapur untuk menuliskan materi seiring dengan kemajuan teknologi yang ada sekarang ruang kuliah sudah dilengkapi dengan peralatan canggih dimana para pengajar dapat menggunakan laptop yang dihubungkan dengan LCD proyektor untuk menampilkan materi yang akan diajarkan. Akan tetapi semakin canggih peralatan yang digunakan manusia, tidak menuntut kemungkinan akan semakin banyak pula jenis potensi bahaya yang akan ditimbulkan seperti radias dari LCD yang di pantulkan ke layar proyektor yang dapat menyebabkan mata panas dan lelah.

Hasil observasi awal yang telah dilakukan ditemukan bahwa ruang kuliah terlihat cukup sempit sehingga mengharuskan LCD proyektor dan layar proyektor diletakkan pada posisi yang cukup tinggi. Penataan meja dan kursi pada ruang kuliah tersebut juga berdempet. Desain seperti itu diketahui menyebabkan mahasiswa belajar dengan postur janggal, dimana mahasiswa harus ekstensi kepalanya untuk dapat melihat materi perkuliahan yang disajikan pada layar proyektor. Penempatan LCD proyektor dan layar proyektor yang dipasang pada posisi tengah juga menyebabkan mahasiswa yang duduk dibagian sayap kanan dan kiri harus memuntirkan kepalanya.

Hasil penelitian yang dilakukan oleh Annas Mahfud (2017) mengenai dimensi ukuran kursi kuliah $67 \%$ responden merasa sudah sesuai dan $33 \%$ menganggap belum sesuai. Pada penelitian Wu (2011) menunjukkan bahwa terdapat beberapa faktor yang mempengaruhi aspek ergonomis dari layar proyektor, meliputi sudut pandang (visual angle) dan kecerahan. Selaras dengan penelitian sebelumnya hasil penelitian Angit Nugroho, dkk (2020) menunjukkan 84\% keluhan yang paling banyak dirasakan mahasiswa/i akibat tata letak proyektor adalah bahu terasa nyeri setelah memperhatikan slide proyektor dari arah samping.

Berdasar informasi diatas maka perlu melakukan penelitian untuk mengkaji apakah desain sarana pendukung proses belajar di ruang kuliah program studi keselamatan dan kesehatan kerja Institusi Pendidikan X menyebabkan keluhan gangguan otot rangka pada mahasiswa.

\section{METODE}

Penelitian ini merupakan analitik bservasional dengan desain study crosssectional dimana data diambil dalam satu waktu yang sama yang dilaksanakan mulai bulan November 2020 sampai dengan bulan Juli 2021 di Institusi Pendidikan X. Besar sampel adalah 42 orang mahaiswa angkatan 2017 dan 2018 dengan rentang kepercayaan $\mathrm{CI}=95 \%$ yang dihitung menggunakan uji rank-spearman. Prosedur pengambilan sampel dengan metode sampel jenuh berdasar kriteria inklusieksklusi yang telah ditetapkan. Jenis data yang dikumpulkan adalah data primer yang dilakukan dengan observasi langsung dan dengan menggunakana instrumen kuisioner keluhan gangguan otot rangka secara subjektif oleh mahasiswa. Analisis univariate dilakukan dengan uji normalitas dan analisis bivariat dilakukan dengan uji rank-spearman.

\section{HASIL}

Data karakteristik responden yang dianalisis univariat menggunakan aplikasi Excel 2016 dalam bentuk distribusi frekuensi dapat dilihat pada tabel berikut:

\section{Tabel 1 Tendensi Karakteristik Individu}

\begin{tabular}{lcc}
\hline $\begin{array}{c}\text { Karakteristik } \\
\text { Individu }\end{array}$ & $\begin{array}{c}\text { Frekuensi } \\
(\mathbf{N = 4 2 )}\end{array}$ & Persentase (\%) \\
\hline Jenis Kelamin & & \\
Laki-Laki & & \\
Perempuan & 17 & 40,48 \\
\hline
\end{tabular}




\begin{tabular}{lcc}
\hline & 25 & 59,52 \\
\hline Usia & & \\
$<20$ Tahun & 1 & 2,38 \\
20-29 Tahun & 40 & 95,24 \\
$>29$ Tahun & 1 & 2,38 \\
\hline IMT & & \\
Kurus & 2 & 4,7 \\
Normal & 21 & 50 \\
Kegemukan & 6 & 14,2 \\
Obesitas & 13 & 30,1 \\
\hline
\end{tabular}

Observasi yang dilakukan pada ukuran dan desain sarana pendukung proses belajar di ruang kelas Institusi Pendidikan $X$ dijabarkan dalam table 2 berikut:

Tabel 2 Ukuran Ruang Kelas dan Sarana Pendukung Proses Belajar

\begin{tabular}{lccc}
\hline $\begin{array}{c}\text { Sarana } \\
\text { Pendukung } \\
\quad \begin{array}{c}\text { Proses } \\
\text { Belajar }\end{array}\end{array}$ & $\begin{array}{c}\text { Ukuran } \\
(\mathbf{c m})\end{array}$ & $\begin{array}{c}\text { Standar } \\
(\mathbf{c m})\end{array}$ & Ket. \\
\hline Kursi & & & \\
Tinggi & 46 & $38-54$ & BS \\
Panjang & 37 & $40-45$ & \\
Lebar & 37,5 & $38-42$ & \\
\hline Meja & & & BS \\
Tinggi & 77 & 74 & \\
Panjang & 55 & - & \\
Lebar & 46 & - & BS \\
\hline LCD & & & \\
Layar & & Setinggi & \\
Proyektor & 290 & pengamat & \\
Tinggi & & pada posisi & \\
& & duduk & \\
& &
\end{tabular}

Sumber : Data Primer, Juni 2021

Ket :

BS = Belum Sesuai

$\mathbf{S}=$ Sesuai

Data jumlah mahasiswa yang memiliki dan tidak memiliki keluhan disajikan pada tabel 3 dan table 4 dibawah ini.

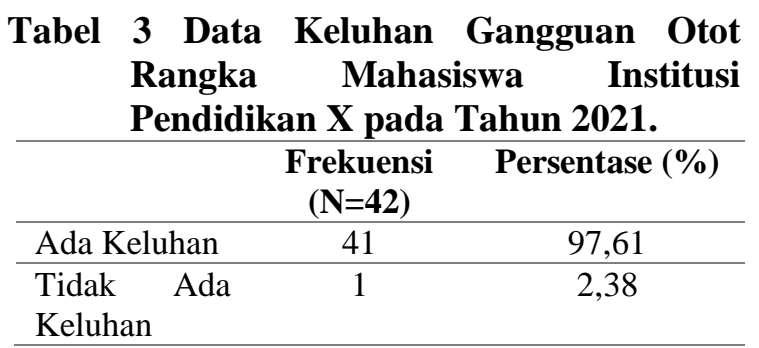

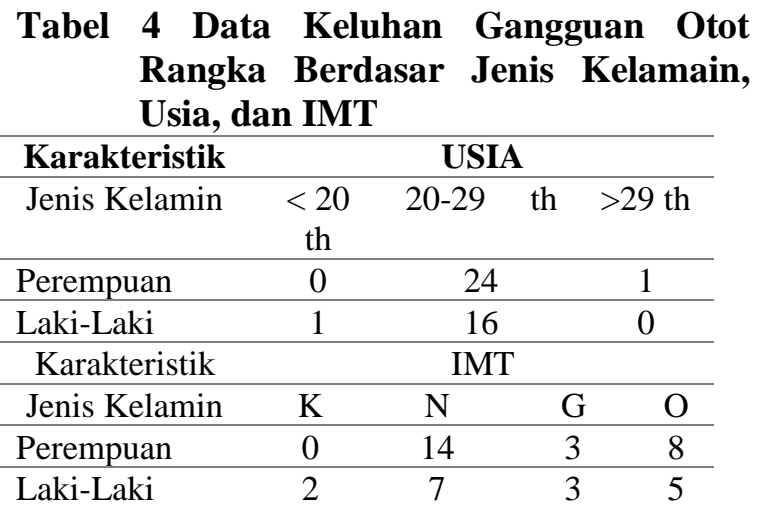

Tabel 5 Data Keluhan Gangguan Otot Rangka Berdasar Usia dan IMT

\begin{tabular}{ccccc}
\hline Karakteristik & \multicolumn{4}{c}{ IMT } \\
\hline Usia & $\mathrm{K}$ & $\mathrm{N}$ & $\mathrm{G}$ & $\mathrm{O}$ \\
\hline$<20$ th & 0 & 0 & 1 & 0 \\
\hline $20-29$ th & 1 & 21 & 4 & 13 \\
\hline$>29$ th & 0 & 0 & 1 & 0 \\
\hline
\end{tabular}

Ket :

$\mathrm{K}=$ Kurus

$\mathrm{N}=$ Normal

$\mathrm{G}=$ Gemuk

$\mathrm{O}=$ Obesitas

Hasil observasi mengenai sebaran bagian tubuh yang mengalami keluhan gangguang otot rangka pada mahasiswa Institusi pendidikan $\mathrm{X}$ dapat dilihat pada Tabel 6 dibawah ini.

Tebel 6 Hasil Observasi Sebaran Keluhan Gangguan Otot Rangka

\begin{tabular}{lc}
\hline \multicolumn{1}{c}{ Bagian Tubuh } & Persentase $(\%)$ \\
\hline Leher & 90,48 \\
\hline Punggung & 76,19 \\
\hline Pinggang & 73,80 \\
\hline Pantat & 76,19 \\
\hline Bahu Kiri & 47,62 \\
\hline Bahu Kanan & 50 \\
\hline Tangan Kiri & 45,24 \\
\hline Tangan Kanan & 38,09 \\
\hline Kaki Kiri & 28,57 \\
\hline Kaki Kanan & 30,95 \\
\hline
\end{tabular}

Berdasarkan hasil observasi pada postur belajar mahasiswa diatas, diperoleh hasil analisis sebagai berikut : 
Tabel 7 Analisi Postur Belajar

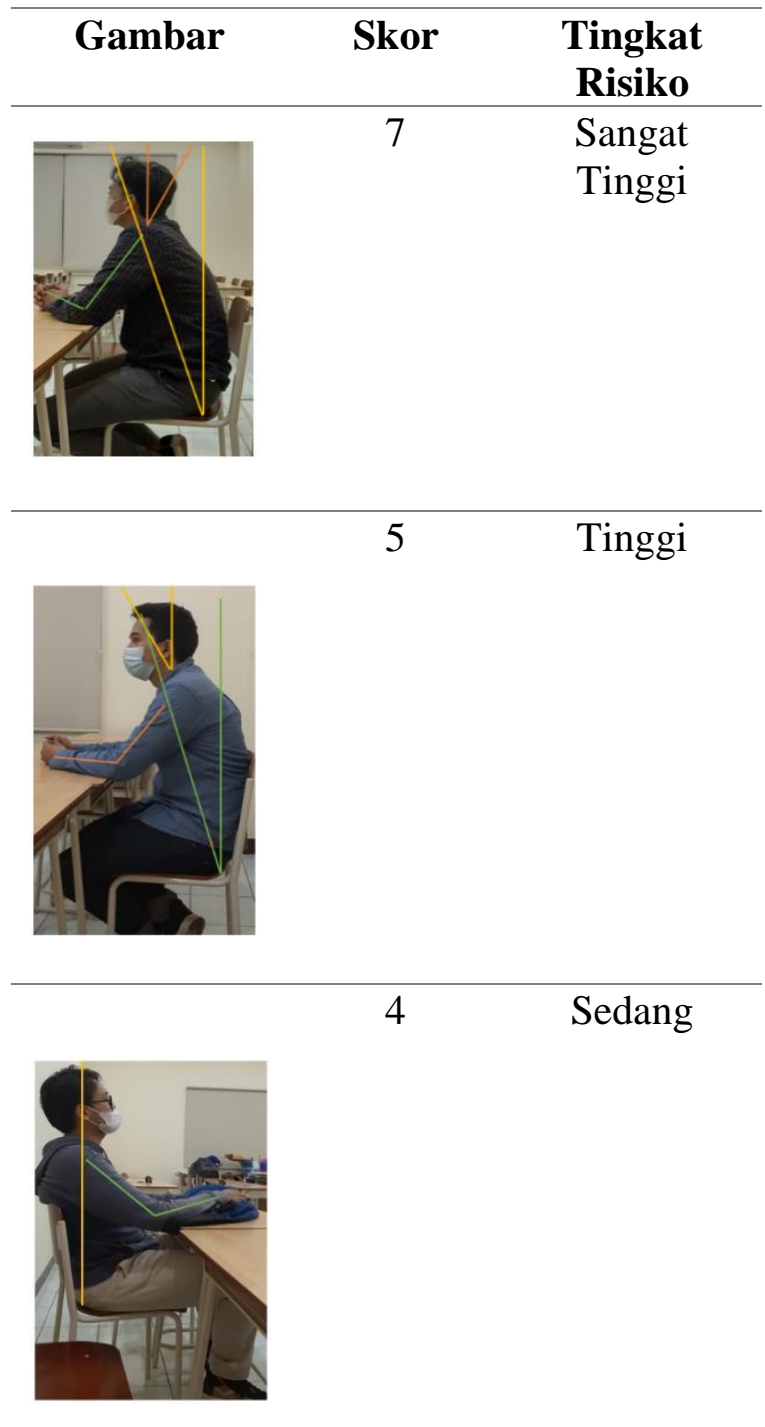

\section{PEMBAHASAN}

Berdasarkan hasil observasi yang dilakukan pada penelitian ini diketahui keluhan pada bagian leher yaitu sebesar $90,48 \%$, kemudian keluhan pada bagian punggung dan pantat sebesar 76,19\%, pinggang $73,80 \%$, bahu kanan $50 \%$, bahu kiri 47,62\%, tangan kiri 45,24\%, kaki kanan 30,95\%, tangan kanan 30,09\% dan yang paling sedikit dikeluhkan adalah pada bagian kaki kiri sebesar 28,57\%. Keluhan-keluhan yang dirasakan mahasiswa diakibatkan oleh kondisi desain sarana pendukung proses belajar yang ada di ruang kelas mereka dan menyebabkan mahasiswa berpostur janggal atau tidak alamiah ketika belajar. Postur-postur janggal atau tidak alamiah yang dialami mahasiswa pada saat belajar seperti kepala mahasiswa yang cenderung ekstensi pada saat belajar dengan menghadap layar proyektor, tubuh mahasiswa yang membungkuk, kemudian kaki yang tidak tertopang dengan baik akibat kursi cenderun kecil serta bahu terangkat karena meja terlalu tinggi.

Postur janggal tersebut menyebabkan mahasiswa merasakan keluhan gangguan otot rangka pada beberapa bagian tubuhnya. Keluhan gangguan otot rangka pada bagian leher yang dikeluhkan mahasiswa dikarenakan layout dari LCD proyektor yang diletakkan pada ketinggian 2,9 meter dari lantai yang kemudian disorotkan ke layar proyektor yangmana penempatan layar proyektor juga dipasang cukup tinggi dengan ketinggian 1,2 meter dari lantai untuk batas bawahnya sehingga kepala mahasiswa cenderung ekstensi saat belajar dengan menatap layar proyektor.

Selain penempatan yang tinggi, layout layar proyektor yang hanya satu dan diletakkan ditengah menyebabkan mahasiswa yang duduk tidak tepat pada depan layar harus memuntirkan atau memiringkan kepalanya kearah samping untuk dapat menatap layar. Keluhan lain yang disarasakan mahasiswa pada bagian punggung, pinggang dan pantat disebabkan oleh karena desain dari kursi yang belum sesuai dengan standar yang ada dengan postur duduk mereka.

Diketahui bahwa ukuran kursi yang dimiliki pada institusi pendidikan $\mathrm{X}$ cenderung kecil dengan panjang 37 sentimeter dan lebar 37,5 centimeter serta memiliki sandaran punggung dan alas duduk yang tegak dan pendek dengan sudut $90^{\circ}$ sehingga mahasiswa duduk dengan tidak nyaman, dan juga bahan kursi tersebut terbuat dari kayu tanpa busa dan juga besi.

Selain keluhan pada bagian punggung, pinggang dan pantat, akibat dari kursi yang cenderung kecil juga 
menyebabkan kaki mahasiswa ketika duduk tidak tertopang dengan baik sehinggan menyebabkan mahasiswa tidak nyaman dan mengeluhkan gangguan otot rangka pada bagian kaki mereka. Terkait dengan keluhan gangguan otot rangka pada bahu dan juga tangan mahasiswa, itu disebabkan oleh karena meja belajar yang digunakan terlalu tinggi sehingga bahu mahasiswa cenderung naik dengan posisi tangan yang menjauhi simetris tubuh.

Jika dikaitkan dengan teori yang ada penyebab tersering terjadinya keluhan gangguan otot rangka antara lain karena adanya tekanan, tarikan, atau beban pada otot skeletal tubuh (Bull dan Archard, 2007). Kemudian postur janggal dimana posisi tubuh menyimpang secara signifikan dari posisi netral dan statis dalam waktu lama dapat menyebabkan kontraksi otot terus menerus dan tekanan pada anggota tubuh (Bridger RS , 2008).

Sebuah kondisi beban berlebih atau adanya tarikan juga dapat membuat posisi tulang, ligamen, atau otot bisa berubah. Pada saat ada beban berlebih, bantalan tulang akan tergeser atau menonjol. Jika hal ini terjadi secara berulang, bantalan antar ruas tulang akan tergeser dan zat yang menyerupai agar-agar di dalamnya bisa tergencet keluar sehingga menekan sel saraf. Hal inilah kemudian yang dapat menyebabkan rasa sakit (Davies, 2007).

Hal-hal tersebut diatas membuktikan bahwa keluhan yang diraskaan mahasiswa benar oleh sebab desain saranan pendukung proses belajar yang tidak ergonomis. Selaras dengan penelitian sebelumnya yang dilakukan Wu (2011) dijelaskan bahwa terdapat beberapa faktor yang mempengaruhi aspek ergonomis dari layar proyektor, meliputi sudut pandang (visual angle) dan kecerahan. Selaras dengan penelitian sebelumnya hasil penelitian Angit Nugroho, dkk (2020) menunjukkan $84 \%$ keluhan yang paling banyak dirasakan mahasiswa/i akibat tata letak proyektor adalah bahu terasa nyeri setelah memperhatikan slide proyektor dari arah samping.

\section{KESIMPULAN}

Berdasarkan dari hasil penelitian dan pembahasan desain sarana pendukung proses belajar (kursi, meja dan LCD proyektor) yang dimiliki ruang kelas prodi K3 pada Institusi Pendidikan X dirancang tidak sesuai dengan prinsip ergonomi sehingga mengakibatkan mahasiswa berpostur janggal pada saat belajar.

Postur janggal pada saat belajar akibat desain sarana pendukung proses belajar yag tidak sesuai prinsip ergonomi mengakibatkan kejadian keluhan gangguan otot rangka yang dikeluhkan mahasiswa pada bagian leher sebesar 90,48\%, keluhan pada bagian punggung dan pantat sebesar $76,19 \%$, pinggang $73,80 \%$, bahu kanan $50 \%$, bahu kiri $47,62 \%$, tangan kiri $45,24 \%$, kaki kanan 30,95\%, tangan kanan $30,09 \%$ dan bagian kaki kiri sebesar $28,57 \%$.

\section{UCAPAN TERIMAKASIH}

Peneliti mengucapkan terima kasih kepada Allah SWT, orang tua, adik-adik, sahabat dan dosen pembimbing akademik yang selama ini telah membantu peneliti dalam menyelesaikan penelitian ini.

\section{DAFTAR PUSTAKA}

Akh Sokhibi, Rangga Primadasa. (2019). Analisis Risiko Musculoskeletal Disorder Pada Tata Letak Lcd Proyektor Ruang Kuliah Fakultas Ekonomi \& Bisnis Universitas Muria Kudus. Jurnal : Spektrum Industri. Vol. 17, No. 2, e-ISSN : 2442-2630. Journal homepage

http://journal.uad.ac.id/index.php/Spekt rum

BNSP. (2011). Rancangan Standar Sarana Dan Prasarana Pendidikan Tinggi Program Pascasarjana Dan Profesi.

Bridger RS. (2008). Intrduction to Ergonomics. Edisi 3. CRC Press. London. 
Bull, Eleanor dan Graham Archard. (2007). Simple Guide Nyeri Punggung. Jakarta: Erlangga.

Corlett EN. (2006). The Occupational Ergonomics Handbook. Edisi 2. CRC Press. London.

Davies, Kim. (2007). Buku Pintar Nyeri Tulang dan Otot. Jakarta: Erlangga.

Data MSDS New York. (2020). terdapat pada:https://www.bls.gov/iif/msd_st ate.htm Diakses pada 1 Juli 2020, Pukul 10.17 WIB

Diana Mayasari dan Fitria Saftarina. (2016). "Ergonomi sebagai Upaya Pencegahan Musculoskeletal Disorders pada Pekerja". Jurnal : Jurnal Kedokteran Unila. Volume 1. Nomor 2. Terdapat pada : https://juke.kedokteran.unila.ac.id/ar ticle (diakses pada 30 Juni 2021, pukul 05.35 WIB)

Distribusi MSDS. Diakses pada 2 Juli 2020. Diakses dari Https://www.bls.gov/iif/oshwc/osh/ os/oshs2008_42.pdf distribusi MSDS 2008

Ejiro Thelma Akhihiero. (2011). "Effect Of Inadequate Infrastructural Facilities On Academic Performance Of Students Of Oredo Local Government Area Of Edo State". Jurnal: The Nigerian Academic Forum Volume 20 No. 1.

Eko Nurmianto. (2015). "Ergonomi Konsep Dasar dan APlikasinya". Gana Widya:Cetakan Kedua. Jakarta.

Gatchel RJ., Kishino ND., \& Strizak AM. (2014).

Occupational Musculoskeletal Pain and Disability Disorders. Dalam R. J. Gatchel dan I. Z. Schultz, eds. Handbook of Musculoskeletal Pain and Disability Disorders in the Workplace. London.

IEA. (2019). Definition, Domains Of Specialization, Systemic Approach. Terdapat Pada Https://Iea.Cc/Definition-AndDomains-Of-Ergonomics/ Diakses pada : 1 Juli 2020, pukul 17.45 WIBIEA-Definisi terdapat pada : Https://Iea.Cc/?S=Definition+Of+Er gonomi Diakses pada 2 juli 2020, pukul 19.11 WIB

IEA. (2020). Definisi terdapat pada : Https://Iea.Cc/?S=Definition+Of+Er gonomi Diakses pada 2 juli 2020, pukul 19.11 WIB

IEA. (2020). Materi terdapat pada : https://Iea.Cc/What-Is-Ergonomics/ Diakses pada 2 juli 2020, pukul 19.30 WIB

IEA (2020). Doamain-Aproach terdapat pada : Https://Iea.Cc/DefinitionAnd-Domains-Of-Ergonomics/

Diakses pada 2 juli 2020, pukul 20.00 WIB

IEA. (2020). terdapat pada : Https://Iea.Cc/ Diakses pada 2 juli 2020, pukul 20.15 WIB

ILO terdapat pada : Https://Ilo.Org/Stat/Areasofwork/St andards/Lfs/Lang--En/Index.Htm Diakses pada 2 Juli 2020, pukul 17.19 WIB

Iriastadi Hardiando, Yassierli. (2014). "Ergonomi Suatu Pengantar". PT Remaja Rosdakarya: cetakan pertama. Bandung.

Kementerian Kesehatan. (2020). Definisi Gotrak terdapat pada : Https: //Www.Kemkes.Go.Id/ Diakses pada : 1 Juli 2020, pukul 15.30 WIB Kementrian Riset, Teknologi, Pendidikan dan Teknologi Informasi. (2019). Peran Sarpras Dalam Persiapan Akreditasi Perguruan Tinggi.

Lfs. (2020). terdapat pada : Https://Www.Hse.Gov.Uk/Statistics /Sources.Htm Diakses pada 2 Juli 2020, pukul 19.27 WIB.

Sutajaya, Made. (2019). "Ergonomi Pendidikan". Media Akademi:Cetakan Pertama. Yogyakarta.

Manuba. (2000). "Ergonomi, Keselamatan dan kesehatan kerja”. Guna Wijaya : Surabaya. 
O’Malley G. (2011). Musculoskeletal Disorders in Obesity. Dalam F. Wilson, J. Gormley, dan J. Hussey, eds. Excercise Therapy ini the Management of Musculoskeletal Disorders. Blackwell Publishing. UK; 2011. hal. 231- 240

OSHA. Ergonomics. (2000). The Studyof Work. In U.S. Department Of Labor Occupational Safety And Health Administration.

PMK No.48 Tahun 2016. Penyebab Gotrak. Statistik Data Muskulus terdapat pada

Https://Www.Hse.Gov.Uk/Statistics

/Overall/Hssh1819.Pdf Diakses pada 1 Juli 2020, pukul 14.28 WIB

Rakhmat Eddy Wicaksono., Suroto., \& Baju Widjasena. (2016). Hubungan Postur, Durasi Dan Frekuensi Kerja Dengan Keluhan Muskuloskeletal Akibat Penggunaan Laptop Pada Mahasiswa Fakultas Teknik Jurusan Arsitektur Universitas Diponegoro . Jurnal Kesehatan Masyarakat (eJournal) Volume 4, Nomor 3, Juli 2016 (ISSN: 2356-3346) http://ejournals1.undip.ac.id/index.php/jkm

Rifqi., \& Amin. (2012). "Faktor Yang Mempengaruhi Kualitas Proses Pembelajaran" dalam https://www.banjirembun.com/2012 /04/faktor-yang-mempengaruhikualitas.html (diakses pada 10 Januari 2020 pukul 19.27 WIB)

Stack T., Ostrom LT., \& Wilhelmsen CA. (2016). Occupational Ergonomics: A Practical Approach Edisi 1. John Wiley dan Sons. New Jersey.

Table of preferred sources for injuries and ill health. Diakses pada 2 Juli 2020.

Diakses dari Https://Www.Hse.Gov.Uk/Statistics /Preferred-Data-Sources.Pdf

Tarwaka., Solichul H.A. Bakri., \& Lilik Sudiajeng. (2004). Ergonomi untuk Keselamatan, Kesehatan Kerja dan Produktivitas. Surakarta: UNIBA PRESS.
Tarwaka. (2014). "Ergonomi Industri Dasar-Dasar Pengetahuan Ergonomi dan Aplikasi di Tempat Kerja”. Harapa Press : Solo.

Tarwaka. (2015). Ergonomi untuk Keselamatan, Kesehatan Kerja, dan Produktivitas. Solo: Harapan Press Solo.

Wignjosoebroto, Sritomo. (2000). Teknik Analisis Untuk Peningkatan Produktivitas Kerja Dalam Ergonomi Studi Gerakan dan Waktu, institute Teknologi Sepuluh November Surabaya, 97-110.

Wijnhovn AH., Henrika CW., \& Picavet HS. (2006). Prevalence of Musculoskeletal Disorders is Systematically Higher in Women than in Men. Clinical Journal of Pain; 22(8): 717-24.

Wowo, Sunaryo. (2017). "Ergonomi dan Keselamatan dan Kesehatan Kerja (K3)". PT Remaja Rosdakarya: Bandung. 